\title{
Weathering the 'perfect storm' facing the mining sector
}

\author{
by N. Singh*
}

\section{Synopsis}

The South African mining industry has made a significant contribution to the country's economy for more than a century. Changes in legislation for mining licences, stricter health and safety targets, and stronger focus on reducing the impact on the environment coupled with increasing labour and electricity costs are some of the factors that significantly changed the landscape in which the mining industry now operates. Further to this, low commodity prices force South African mines to seek new, more technically advanced, cost-effective ways of increasing production without compromising occupational health and safety.

Research, development, and innovation (RD\&I) in the mining sector is therefore required to find solutions that are cheaper, safer, and more efficient. Alternative programmes must be developed and put in place to transform South Africa's comparative mineral endowment advantages into more sustainable and globally competitive strengths.

This paper discusses the recently developed and accepted South African Mining Extraction Research, Development \& Innovation (SAMERDI) strategy, which is strongly focused on productivity-related issues in order to ensure that mineral resources can be converted into mineable reserves economically, safely, and with minimal impact on the environment. Furthermore the paper will discuss the merits of revitalizing the mining RD\&I environment through the strenghtening and consolidation of efforts in a manner that is collaborative and ultimately sustainable.

\section{Keywords}

South African mining, competitiveness, productivity, innovation, research and development.
Detonation of the explosives is now done in a much more controlled and coordinated manner, by the use of centralized blasting and electronic detonators rather than the manual lighting of each fuse by the miner as in the early days of mining

> Scrapers and winches for cleaning, which were introduced in the 1920s, are still in use today

> Support systems, to this day, consist of combinations of in situ pillars, backfill, wood, and steel.

\section{Mining in South Africa}

South Africa's mineral resources endowment is the foremost in the world, not only as regards gold and platinum group metals (PGMs) but also manganese and chromium, to name but a few. The minerals industry contributes significantly to South Africa's internal energy requirements, trade balance, internal investment, domestic savings, foreign capital, and direct and indirect employment creation. Mining has made a significant contribution to the South African economy for more than a century. Many of the challenges facing the domestic minerals sector over the medium to long-term parallel those at the global level.

\section{Introduction}

The underground coal mining industry underwent a resurgence when blasting was replaced by the use of continuous miners. Not only were there significant improvements in productivity and efficiency; the safety record improved dramatically. Hard rock underground operations have not made this major transition, despite significant efforts to develop similar technology for narrow-reef, tabular metalliferous mines. Metalliferous underground mining in South Africa industry is carried out using cyclic drilling and blasting operations. Although there have been improvements over time, these have been small and incremental.

> Ore is still broken from the host rock by the use of explosives, which requires blast-holes to be drilled into the rock mass
> South Africa faces increased competition in terms of attracting foreign direct investment in the minerals sector

> Mining horizons within existing orebodies are becoming deeper and more difficult to access and extract, necessitating the adoption of mechanized extraction methods, optimization of

* CSIR, South Africa.

(C) The Southern African Institute of Mining and Metallurgy, 2017. ISSN 2225-6253. This paper was first presented at the New technology and innovation in the Minerals Industry Colloquium', 9-10 June 2016, Emperors Palace, Johannesburg, South Africa. 


\section{Weathering the 'perfect storm' facing the mining sector}

existing process flow sheets, and the development of new and improved methods to increase efficiency and improve recoveries

> There is an increasing push for the development of technologies capable of maximizing energy and water efficiency and ensuring environmental integrity

- Furthermore, as prices across all the mining commodities continue in a downward trend, marginal mines face an ever-increasing risk of closure and thus the post-mining rehabilitation and regeneration of mine land is another critical issue that needs to be addressed now.

\section{The components of a perfect storm}

A 'perfect storm' is a detrimental or calamitous situation or event arising from the powerful combined effects of a unique set of circumstances. In relation to the South African mining industry the issues can be summarized as follows.

> The ubiquitous need to ensure that the target of zero harm is achieved with regard to occupational health and safety

> The South African gold industry is characterized by decreasing production, increasing depth of operations, and harder-to-access payable material

> Labour and other costs have increased significantly and have adversely affected the profitability and sustainability of gold mining in South Africa

> South Africa dominates global production of PGMs. Labour costs and rising steel and electricity costs all result in profitability being marginal in terms of operational costs

$>$ In the iron ore industry, transport infrastructure and transport costs are major problems. The low commodity price as well as the decrease in the demand for steel has had a negative impact on this sector

> The need to ensure that mine rehabilitation requirements are well resourced and funded so that the environmental impact is minimized both during mining as well as once mining activities cease

> The skills shortage from a technical as well as operational perspective

> Socio-economic issues, especially in communities where mining operations are located.

Figure 1 is a graphical representation of the challenges facing the mining industry. As per the definition, it can be postulated that the South African mining sector is facing a perfect storm.

The severity of the challenges facing the South African mining industry is summarized in the following points that were raised during various mining stakeholder forums. The Chamber of Mines (Baxter, 2016) reported that:

> 59407 jobs were lost between 2012 and 2015

> Productivity has declined in the gold and platinum sectors

> Mining's contribution to the GDP declined from $21.9 \%$ in 1970 to just $5.1 \%$ in 2014

> Having led the world in gold production in 2006, South Africa now ranks 7 th

> Easy accessible resources, especially in gold, are becoming depleted
> The industry has left a legacy of environmental problems, including acid mine drainage.

\section{All hands on deck}

Following the Malaysian model for quick tangible results, the South African government-led Phakisa process (Department of Planning, Monitoring and Evaluation, n.d.) was applied in areas that would help foster growth and the attainment of national development goals. Phakisa is essentially a collaborative process, convened by government but involving a range of key stakeholders, to plan and oversee the implementation of initiatives that will have a positive impact on the economy and society. Mining is one such area (South African Government News Agency, 2016).

The mining cluster is facing deep-seated economic and socio-economic historical, structural, and immediate challenges. Phakisa is tasked with developing collaborative interventions that will have a meaningful impact on the short- and medium-term challenges faced by the mining cluster, and putting in place institutional mechanisms that will entrench collaboration. The broad aim of the Mining Phakisa is to galvanize growth, transformation, investment, and employment creation along the entire mining value chain, in relevant input sectors and in mining-related communities.

Stakeholders from the mining industry, organized labour, government departments, and research organizations agreed to endeavour to 'extend the life of Platinum and Gold mines in South Africa beyond 2025 and establish global leadership in narrow-reef, hard rock mining systems'. Furthermore, 'this is enabled through partnerships in research and development, skills and competitive local manufacturing capability that will focus on the current and future mining operations through next generation mining systems. To achieve this, a just transition must be at the core' (South African Government News Agency. 2016).

Many leaders of mining companies have spoken of the need to modernize mining in the country. However, modernization is often confused with mechanization. Modernization may involve mechanization, but it is more than just mechanization.

Modernization of mines through mechanization and automation, and ultimately fully autonomous operations, is the envisaged path that will bring change to processes, technologies, skill-sets, and social and environmental impacts associated with current mining practices. This was echoed by

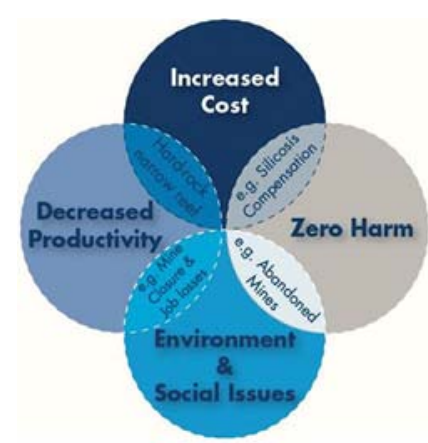

Figure 1-Challenges facing the South Africa mining industry 


\section{Weathering the 'perfect storm' facing the mining sector}

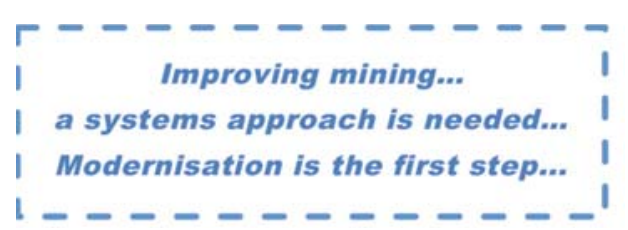

Anglo Platinum CEO, Chris Griffith 'Modernisation is not just about innovation, new technologies, mechanisation and automated processes. We will only attain our vision of a modern mine if we work in partnership with our employees, government, unions and NGOS' (Griffiths, 2015).

A vibrant, strongly capacitated, and adequately resourced local mining $R \& D$ community is needed to ensure that the solutions are designed for South African conditions from a socio-economic as well as technical perspective, due to the nature of South African mining conditions and the complexity of addressing the social imbalances of the past.

\section{A strategy for mining}

In November 2014, under the leadership of the Deputy Minister of Mineral Resources, Mr Godfrey Oliphant, stakeholders discussed $R \& D$ within the mining sector. During the discussions, the CSIR was tasked with developing a consolidated mining strategy utilizing the draft documents of the Department of Science and Technology (DST) (Craven et al., 2014) and the Department of Mineral Resources (DMR) (Vogt and McGill, 2014). The resulting document was entitled the South African Mining Extraction Research, Development and Innovation (SAMERDI) Strategy.

At the core of the SAMERDI strategy, aligned to the visions, are the following objectives:

i. To improve the competitiveness of the sector and create new opportunities for South African based companies to operate in areas along the entire value chain from the innovations stemming from the RD\&I areas

ii. To reposition South Africa as the world leader in mining RD\&I by building human resources skills, capabilities, and capacities across industry, academia, and the science councils to ensure its sustainability.

\section{The solution design}

SAMERDI served as an input document into the Mining Phakisa that was held in November 2015. Although the Mining Phakisa outcomes have not been formally announced by the Office of the Presidency, there have been significant developments during the process.

- Firstly, stakeholders agreed that the SAMERDI strategy would be the consolidated strategy for mining extraction after consolidation with the inputs of the Chamber of Mines

> Secondly, there is a collective agreement by stakeholders in that there is a need to strengthen mining extraction research capabilities and capacity in South Africa as the sector moves towards modernization. Stakeholders agreed that consolidation of the various resources and research offerings in one common space is necessary

> Finally, there was agreement on the need to develop systems that will migrate current mining from conventional, labour-intensive, highly diluted methods to the utilization of mechanized drilling and blasting equipment, and ultimately to a continuous mining method that is independent of the use of explosives.

To this end, two focus areas were developed.

1. Mining $R \& D-\mathrm{An}$ intensively collaborative research and development model with a holistic systems approach, that is substantially funded and which will focus on core technologies, patents, and commercialization opportunities and ultimately position South Africa as a global leader in developing solutions for narrow-reef hard-rock mining

2. Mining manufacturing equipment cluster- A mining manufacturing equipment cluster that is embedded with other existing clusters and initiatives, which will ensure that development requirements are translated into coherent $R \& D$ programmes, enabling local partnerships to develop and manufacture equipment for next-generation mining systems.

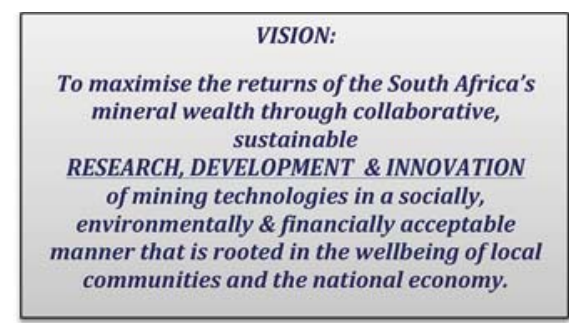

Figure 2-Vision of SAMERDI strategy

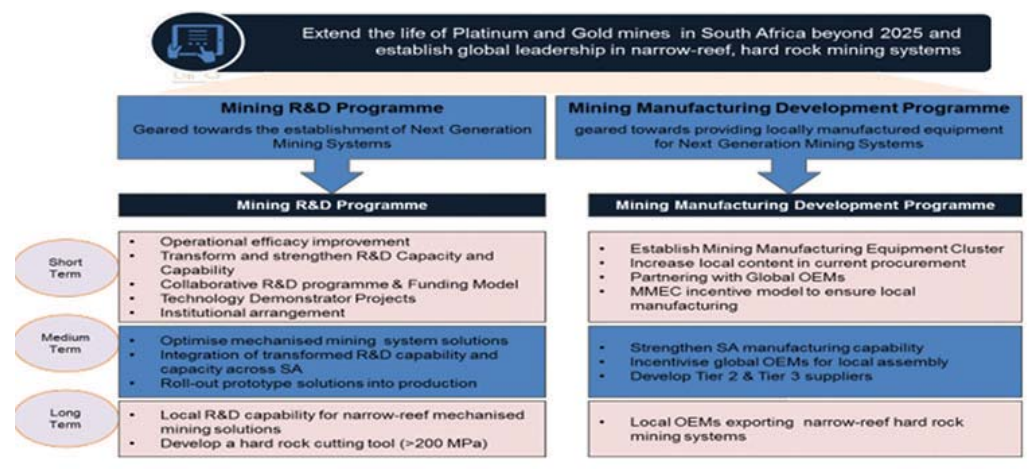

Figure 3-Advancing the mining cluster 


\section{Weathering the 'perfect storm' facing the mining sector}

\section{Collaborative R\&D approach - 'all hands on deck'}

The South African mining $R \& D$ environment is very fragmented compared to other countries. South Africa does not currently have any single, central entity to guide and coordinate innovation in the mining industry. Instead, there are number of mining-related collaborative initiatives such as:

a) Centre for Sustainable Mining Industries (CSMI) University of the Witwatersrand

b) Centre for Mechanised Mining Systems (CMMS) University of the Witwatersrand

c) Wits Mining Institute (WRI) - University of the Witwatersrand

d) Mining Resilience Research Centre (MRRC) University of Pretoria

e) Centre of Excellence on Occupational Health and Safety (CoE) - Mine Health and Safety Council

f) Mining Research Impact Area (RIA) - CSIR.

Efforts to spread financial support across these various institutions in South Africa have led to a situation where there is insufficient critical mass in any one field, resulting in research capability and capacity, and thus offerings, deteriorating. There is a dire need for a vibrant, strongly capacitated, and adequately resourced local mining RD\&I community to ensure that the solutions for the South African mining industry address local socio-economic as well as technical challenges as identified in the SAMERDI strategy. Until now, research providers have had to compete for limited funding. The end result of this process saw the erosion of research capability and capacity, which led to a loss of confidence in the ability to develop new solutions and further reductions in $R \& D$ investments due to lack of capability. The SAMERDI strategy aims to counter the erosion of research capability by striving for true collaboration as follows:

1. To improve the competitiveness of the sector and create new opportunities for South African based companies to operate in areas along the entire value chain from the innovations stemming from the RD\&I areas

2. To reposition South Africa as the world leader in mining RD\&I by building human resources skills, capabilities, and capacities across industry, academia and the science councils, ensuring its sustainability.

\section{Enhancing the competiveness of mining sector}

Since the completion of the Mining Phakisa in November 2015, significant work has been done under the leadership of the Department of Science and Technology (DST) through the CSIR and the Chamber of Mines in developing programmes of work for the implementation of the SAMERDI strategy, viz.:

(i) Modernization of current mining operations-The focus is on increasing the efficiency of extraction, improving occupational health and safety, and reducing costs

(ii) Mechanized drill and blasting-The development fully mechanized mining systems that will allow remote drilling and blasting in narrow-reef hard rock mines (in particular the gold and platinum mines)

(iii) 24/7 non-explosive rockbreaking-The development of complete mining systems for extraction that are entirely independent of the use of explosives. (iv) Advanced orebody knowledge-Mechanization and modernization of mining requires better knowledge of the orebody ahead of the mining face. This project aims to 'make the rock transparent', so that instead of mining blind, an accurate 3D real-time model can be used for safety and planning

(v) Real-time information management systems-The inability to accurately monitor issues in real time poses a significant challenge across the entire mining process, even more so when using mechanized mining methods. Production-related issues have a direct impact on the efficiency of the mines. Using real-time information for monitoring and control allows proactive intervention that can correct deviations and unsafe conditions

(vi) Human factors-Modernization via automation and mechanization of South African mining processes will have significant implications for the number of people employed in the industry, as well as the required skills levels. This will also require attention as regards change management issues. The requirements for the upstream and downstream processes associated with mechanization will have to be understood.

For each of the above areas, research questions were developed in the areas identified by members of the Chamber of Mines Innovation Task Team (Table I).

\section{Rebuilding and repositioning South Africa as the world leader in mining RD\&I}

The rebuilding of mining $R \& D$ capability requires a twopronged approach:

1. The establishment of a forum or community of researchers-The hub-and-spoke model was adopted since it provides the opportunity to leverage the existing capabilities of various research organizations while utilizing the administrative strengths of the host organization. A central core management team will serve as the 'hub' and coordinate the work programmes. The researchers from mining-focused research institutes (universities and science councils) will serve as research providers and thus act as the 'spokes'. Figure 4 provides an overview of the process listed below:

(i) Researchers from the identified research organizations (universities and science councils) will form teams to collectively develop solutions

(ii) Representatives from the various research organizations will participate in a series of workshops and meetings to form teams based on the mix of skills and capabilities

(iii) The research teams will develop proposals and submit them to a committee made up of appropriate subject-matter experts from industry for comment

(iv) Project proposals must indicate the level of collaboration. If a proposal is submitted that does not have all four research providers' inputs, the parties not included must provide reasons for their non-participation. 


\section{Weathering the 'perfect storm' facing the mining sector}

\begin{tabular}{|c|c|}
\hline \multicolumn{2}{|c|}{ Research questions per thematic area } \\
\hline Thematic area & Research question \\
\hline Modernizing current mines & $\begin{array}{l}\text { - How can we improve the safety and health of employees as well as the profitability } \\
\text { of existing operations? }\end{array}$ \\
\hline Mechanized mining for gold and platinum & $\begin{array}{l}\text { - What are the system requirements to ensure the successful application of mechanized mining } \\
\text { (including partial, hybrid, and full mechanization)? }\end{array}$ \\
\hline Non-explosive rockbreaking & $\begin{array}{l}\text { - What are the critical rock engineering requirements to ensure the stability of the rock mass so } \\
\text { that that mining can be undertaken? } \\
\text { - What rockbreaking mechanism is most appropriate for both gold and platinum operations? }\end{array}$ \\
\hline Advanced orebody knowledge & $\begin{array}{l}\text { - What techniques and technologies could be used to 'see' } 30 \mathrm{~m} \text { through rock underground, and to } \\
\text { model the orebody and surrounding rock in } 3 \mathrm{D} \text {, in multiple characteristics? }\end{array}$ \\
\hline $\begin{array}{l}\text { Real-time information management systems } \\
\text { Human factors. }\end{array}$ & $\begin{array}{l}\text { - What are the appropriate means and systems to enable real-time communication between the } \\
\text { operating face of the mine and the surface? } \\
\text { - How can resistance to change be overcome, (covering all levels in the organization, and } \\
\text { extending across the mining value chain)? Studies to be undertaken across all mining companies } \\
\text { and OEMs to research and consolidate these failures, so as to design practical solutions and strategies }\end{array}$ \\
\hline
\end{tabular}

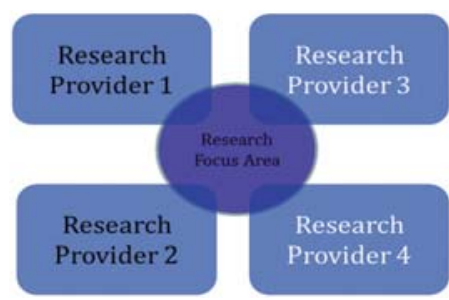

Figure 4-Model for collaboration

\section{Facilitation of collaboration - a Mining Precinct - 'Minds for Mines'}

The nature of the mining $R \& D$ environment does not necessarily imply that the already established centres, as mentioned above, are ineffective or not essential. However it does imply that the model for collaborative working needs to be further investigated and revisited. The CSIR premises at Carlow Road in Auckland Park, Johannesburg has been revitalized to form the Mining Precinct.

The Mining Precinct will serve as a nerve centre for $R \& D$ activities that could be spread across many geographical boundaries. The Mining Precinct will provide an environment for collaboration utilizing modern means of communication. Figure 5 shows the Carlow Road facility and the various buildings on the site that provide the following facilities.

> Building 1-This will be the main office complex and will house (either temporarily or permanently) the researchers and the administrative functions of the Mining Precinct. The details of the occupants in the building will be dealt with later in the document

> Building 2-This is planned as a learning centre, which will include an auditorium for hosting conferences and symposia. This facility will attract mining stakeholders to the Mining Precinct and thus provide opportunities for further engagement with the researchers

> Building 3-This houses the existing testing facilities for rock engineering support systems and ventilation services. Considering the critical functions of both these disciplines in mining sector, it is envisaged that the facilities could be revamped and upgraded.

Furthermore, the other buildings and workshops can be revitalized to function as mining laboratories and test facilities, such as a backfill laboratory. Other state-ofthe-art laboratory facilities may be established for mine design, rock drilling and cutting, mechatronics and robotics, multiple-use sensors, geophysics, geometallurgy, and mine digitization

> Warehousing and workshop space-The large warehouse at the back of the premises would be ideal for building a mock stoping and development end that can be used to simulate mining conditions, allowing for the development of concepts and testing of research hypothesis before embarking on full-scale in-situ testing.

\section{Enhancing manufacturing capability - 'South African OEMs to the rescue'}

The other significant aspect of Advancing the Cluster is the need to develop a manufacturing capability for mechanized mining equipment designed to operate in narrow tabular orebodies. The development of technologically advanced equipment can be described with reference to various stages, or 'technology readiness levels' (TRLS) as developed by NASA in the 1970s (Mankins, 1995). Figure 6 is conceptual diagram showing the quantum of funding required for the development of technology solutions and the relationship between state funding and industry funding. For $R \& D$ purposes, only those initiatives at TRL 6 and below will be

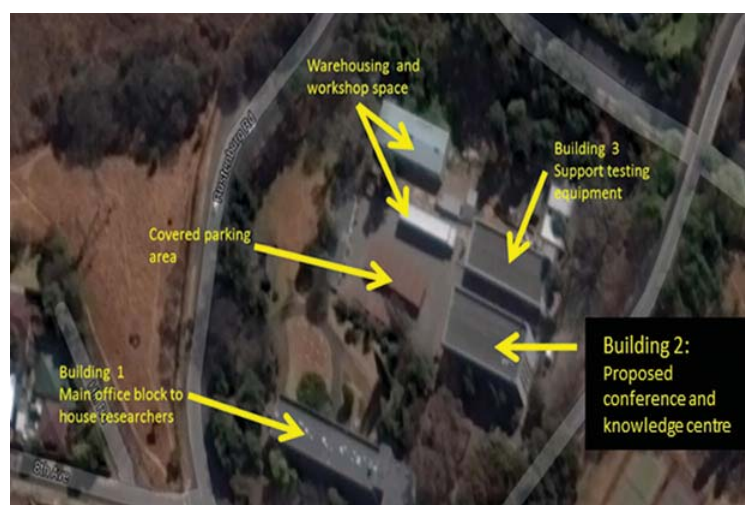

Figure 5-The Mining Precinct 


\section{Weathering the 'perfect storm' facing the mining sector}

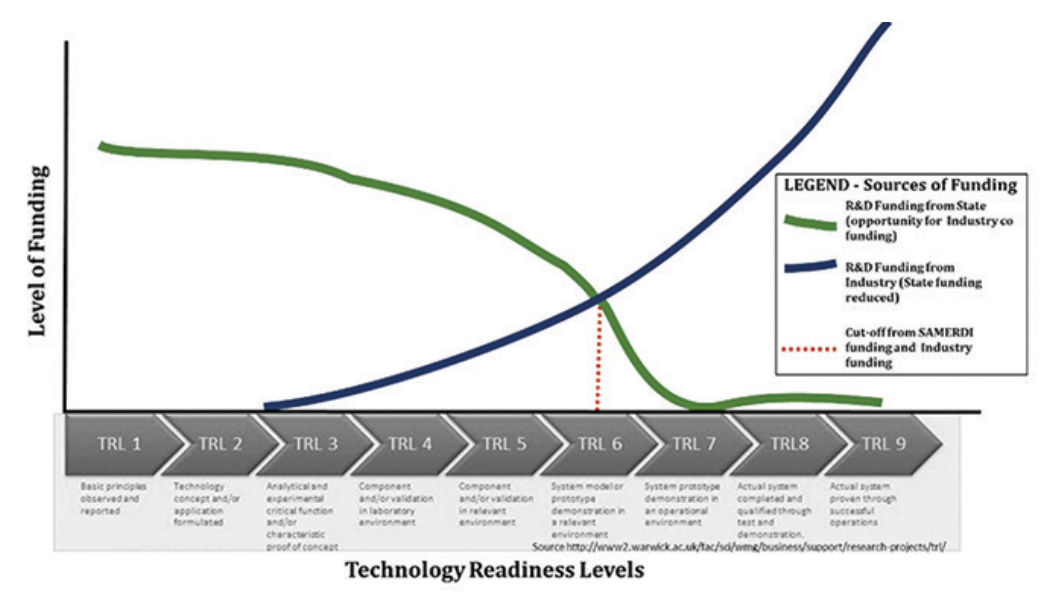

Figure 6-Quantum of funding required and sources of funding according to TRL (Alastair MacFarlane, Chamber of Mines)

considered for funding. Technologies above TRL 6 will be allocated to the mining equipment manufacturers for development into commercialization opportunities. There is opportunity for the mining industry to provide funding in both areas (with the state and with the OEMs).

\section{South African solutions for South African problems}

Current labour-intensive methods of mining tabular gold deposits are increasingly expensive, and not conducive to the objective of zero harm. It is therefore imperative to design and develop an integrated mining system that allows the mining of deeper and lower-grade reefs, cost-effectively and safely, for the sustainability of the industry.

The first and foremost aim of developing mechanized mining solutions is to improve safety, health, and the effectiveness of underground narrow-reef mining operations, which are still based on cyclical drill-and-blast operations. The objective is to remove the operators from the working faces, thus reducing their exposure to the 'danger area', while employing technology that is rugged, capable of negotiating mining dips and narrow (less than $1 \mathrm{~m}$ ) widths, while ensuring accuracy and efficiency. In addition, the project aims to deliver increasing ore reserves and production.

With the call for modernization of South African mines and the nature of the orebodies (depth, reef width, and the dip of the reef), the solutions that need to be sought will be uniquely South African. Mechanization is not a new concept in the South African mining sector and has been used with varying degrees of success for different mineral commodities, particularly in the coal mining sector and most recently in some platinum operations. Gold mines have had the least successes of all in deploying mechanized (trackless) mining, except for two mines that exploit massive orebodies. Previous attempts to mechanize mines, gold mines in particular, have not been sustainable, either because of cost, or because of management intervention to return to conventional methods. The depth of mining, the steep angle of the orebodies, as well as the narrow width of the reef package will require significant investment in RD\&I to understand the various challenges such as rock engineering requirements, the mechanical design of the equipment, and related ventilation flow into the mines. To this end, a detailed programme has been developed for the mechanization of gold and platinum mines. The approach to mechanization is seen as twophased:

- Mechanization that is still based on a cyclic drill and blast approach

> Full mechanization that is independent of the use of explosives and employs some mechanical form of rockbreaking.

Figure 7 shows some of the mechanized mining solutions being considered by South African mining operations.

Irrespective of the manner of mining using mechanization, the solution that is sought is a full systems approach that covers all the mining activities associated with either stoping or development (inclusive of rockbreaking, support installation, as well as tramming and hauling). The development of the Mining Equipment Manufacturing Cluster was supported by the Department of Trade and industry (DTI) and led to the formation of MEMSA. It is envisaged that MEMSA will help position South African mining capital goods manufacturers as a world-class, competitive, innovative, dynamic and transformative industrial cluster, through which South African OEMs will be able to develop and export mechanized narrow-reef hard-rock mining equipment.

\section{Just transition}

While modernization and technological innovation are paramount to the future of the mining sector, the human consequences of introducing change also need to be considered. Modernization will have a direct impact on the workforce, and inevitably on the number of people employed in mining. This will have a follow-on effect on the communities dependent on mining. Therefore as well as the technical challenges, such as the development of suitable technologies, and mining and geotechnical constraints, critical aspects such as change management and leadership, re-skilling, training requirements, work planning and operation of the mine, and relationships with supporting industries need to be considered.

\section{Conclusions}

The need to access and process low-grade mineral deposits that lie at greater depths, under more complex geotechnical constraints, in areas with sparse infrastructure, coupled with increasing calls for maximum socio-economic returns from 


\section{Weathering the 'perfect storm' facing the mining sector}

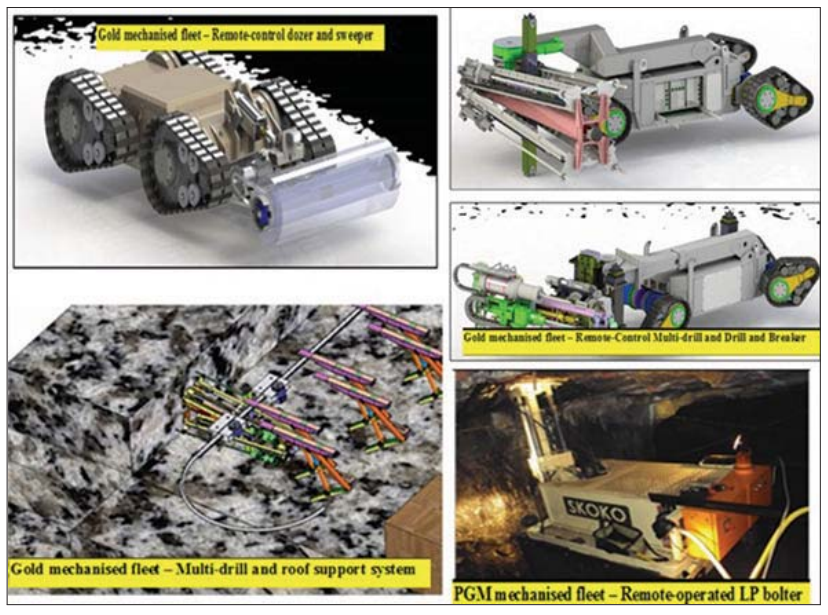

Figure 7-Some examples of potential mechanized mining solutions under consideration

mining, and increasing costs of energy, water, and labour, constitutes the perfect storm.

All stakeholders in the industry agree that ensuring the longevity of the South African mining sector will require a coherent, collaborative approach to the current and future challenges.

The plateauing of production, set against the constant increase in costs, the ubiquitous need to improve safety, and a depressed global market with commodity prices forecast to remain low for years to come, necessitates the revitalization of mining $R \& D$ capabilities in South Africa.

The South African Mining Extraction Research, Development \& Innovation (SAMERDI) strategy provides a roadmap on working collectively towards technological solutions that will increase safety and productivity, reduce costs, and ultimately extend the life of mines.

Thus the implementation of SAMERDI strategy through collaboration and support from researchers (science councils and academia), government departments, mining houses (individually and collectively), and organized labour unions can be the solution to weather the perfect storm that besets the mining sector.

\section{Acknowledgments}

The CSIR is thanked for allowing the time to publish this paper. The work was done partly in conjunction with the Chamber of Mines, and the contributions of Mr Alastair MacFarlane and Mr Katlego Letsoalo are appreciated and acknowledged.

Further acknowledgments are extended to Mr Imraan Patel, the DDG of the DST; Mr Beeuwen Gerryts, Chief Director of the DST; Mr Llandley Simpson, Director of Advanced Minerals and Deputy Director; and Ms Candice Willard for their efforts and leadership in the DST programme 'Development of a South African Research Agenda for Mining And Geosciences' that led to the Rock Innovation Programme.

The members of the DMR, and in particular those involved in the Mining Industry Growth Development and Employment Task Team (MIGDETT), are thanked for their foresight in undertaking the DMR project 'A Technology Innovation Roadmap for the South African Minerals Industry'.
It is therefore with full gratitude that the following people are recognized for their individual and collective efforts in the drafting of the initial documents for the DST and DMR:

> Peter Craven, Mintek

- Stewart Foya, Council for Geosciences

> Marian Lydall, Mintek

> Declan Vogt, University of the Witwatersrand

> Jeannette McGill, Anglo Platinum

> Alan McKenzie, Mintek

A special acknowledgement to the Deputy Minister of Mineral Resources, Mr Godfrey Oliphant, for his leadership in driving the initial processes of collaboration and coordination towards a consolidated mining RD\&I strategy.

Finally, the members from the various stakeholder groupings involved in the RD\&I workshops on mining as well as the Mining Phakisa are acknowledged for their inputs and comments.

\section{References}

BAXTER, R. 2016. Mining in South Africa the challenges and opportunities. http://www.chamberofmines.org.za/industry-news/publications/presentations/send/7-2015/269-mining-in-south-africa-the-challenges-andopportunities

Craven, P., Lydall, M., Vogt, D., Foya, S., and McGill, J. 2014. A technology innovation roadmap for the South African minerals industry. Department of Mineral Resources, Pretoria.

Department of Planning, Monitoring and Evaluation. Not dated. Operations Phakisa. Office of the Presidency.

http://www.operationphakisa.gov.za/Pages/Home.aspx

GRIFFITHS, C. 2015. Modernisation - building a sustainable mining industry in South Africa. Address at the Mining Indaba.

http://www.angloamerican.com/media/our-stories/modernisationbuilding-mining-in-sa

MacFarlane, A. 2017. Chamber of Mines. Personnel communications

MANKINs, J.C. 1995. Technology readiness levels. White Paper, NASA. http://www.hq.nasa.gov/office/codeq/trl/trl.pdf

South African Government News Agency. 2016. Mining Operation Phakisa to start work in August. http://www.sanews.gov.za/south-africa/miningoperation-phakisa-start-work-august

SingH, N. 2015. South African Mining Extraction Research, Development \& Innovation Strategy. Department of Science and Technology. (Unpublished)

VoGT, D. and McGill, J. 2012. Development of a South African research agenda for mining and geosciences- part C: the agenda. Department of Science and Technology, Pretoria. (Unpublished).

Zuma, J. 2016. State of the Nation Address. http://www.gov.za/speeches/president-jacob-zuma-state-nation-address2016-11-feb-2016-0000 